\title{
Review
}

\section{Sensors for the improvement of irrigation efficiency in nurseries}

\author{
Nkosinathi D Kaptein ${ }^{1,2 *}$, Marnie E Light ${ }^{1,3}$ and Michael J Savage ${ }^{2}$ \\ IInstitute for Commercial Forestry Research, Pietermaritzburg, South Africa \\ ${ }^{2}$ Soil-Plant-Atmosphere Continuum Research Unit, School of Agricultural, Earth and Environmental Sciences, \\ University of KwaZulu-Natal, Pietermaritzburg, South Africa \\ ${ }^{3}$ Research Centre for Plant Growth and Development, School of Life Sciences, University of KwaZulu-Natal, Pietermaritzburg, South Africa
}

\begin{abstract}
Traditional timer-based systems for irrigation management, which are more commonly used in commercial nurseries in South Africa, are not ideal as they may not irrigate seedlings efficiently. A sensor-based irrigation system is presented as an alternative, as this can provide several benefits to nurseries and nursery-grown seedlings. Small-sized soil water sensors that could fit in small-volume nursery containers $(25$ to $100 \mathrm{~mL}$ ), and could be integrated into an automated irrigation system, are reviewed. Several experiments have been conducted internationally to measure soil water status of small-volume containers in soilless substrates, and a large body of knowledge is now available. In this review, we describe the principles of several currently commercially available sensors that can be adapted to this purpose, giving advantages and disadvantages of each type. We conclude that a sensor-based irrigation system has great potential to address the challenges associated with irrigation scheduling, while improving water usage in most nurseries.
\end{abstract}

Keywords: automation, porous substrates, seedlings, small-volume container, timer system

\section{INTRODUCTION}

Irrigation water is becoming increasingly scarce in South Africa, with the agricultural industry using approximately $62 \%$ of available fresh water (Pimentel et al., 2004; Fanadzo and Ncube, 2017). Ever-increasing demand for this limited resource for household and industrial use, as well as recent droughts, has resulted in an urgent need for water conservation (Gleeson et al., 2012). Thus, in commercial nurseries which support the agricultural and forestry sectors, it is becoming increasingly important to develop efficient irrigation systems. Improved irrigation practices by nurseries can save water and reduce the costs of irrigation, and have the potential to improve seedling quality, reduce leaching of nutrients, and lower the incidence of pathogen infestation (Belayneh et al., 2013; Lichtenberg et al., 2013; Bayer et al., 2015; Saavoss et al., 2016; Lea-Cox et al., 2017; Wheeler et al., 2017). Many biological and biophysical processes, such as seed germination, seedling nutrition and growth, as well as transpiration and evaporative cooling, are dependent on sufficient moisture via efficient irrigation (Bittelli, 2010; 2011). In most commercial nurseries, seedlings are grown in containers with small-volume cavities ranging from 25 to $100 \mathrm{~mL}$ (examples of some forestry seedling containers are shown in Fig. 1; Durner, 2013). This optimises the utilisation of nursery and transportation space while ensuring the best performance when planted in the field. In such containers, plant roots have a limited substrate volume to explore for water. Although space saving, one of the difficulties with these containers is that the substrate water status can range from near-saturation immediately after irrigation, to neardryness after several hours without irrigation (Van Iersel et al., 2011; Montesano et al., 2016; Lea-Cox et al., 2017). Irrigation scheduling for these containers should, therefore,

*Corresponding author, email: nkosinathi.kaptein@icfr.ukzn.ac.za Received 20 November 2017; accepted in revised form 26 June 2019 aim at maintaining the media water content at levels that minimise seedling water stress and maximise irrigation efficiency during periods that require stress-free growth (Van Iersel et al., 2011).

Commercial nurseries generally irrigate their seedlings based on the visual appearance of the substrate (wet or dry), their intuition and experience (growers may pick up the container to feel its relative 'weight'), and often rely on a fixed timer-based system (Jones, 2004; 2008; Lea-Cox et al., 2011; 2017). Although the settings of a timer-based system can be adjusted, it is set to irrigate according to a predetermined schedule to apply water at a particular time of day and for a particular duration (Nemali and Van Iersel, 2006; Montesano et al., 2016). Such timer-based systems have been widely adopted due to their ease of use, relatively low cost, ease of programming and success in irrigating correctly when managed closely during periods of peak water demand (Nemali et al., 2007; Lea-Cox, 2012). However, they can be ineffective and inefficient since water requirements may vary by species, season, microclimate and changes in root density or leaf area as the plant grows (Lea-Cox, 2012). For example, such systems can waste water on cooler and cloudy days due to fixed irrigation schedules which operate irrespective of weather changes (Van Iersel et al., 2011). In addition, most nursery managers are risk averse, preferring to apply excess water to ensure against system failure or heterogeneity of application (Jones, 2004; 2008). However, with increasing water costs and restrictions, it is becoming more necessary to limit excessive water application. Therefore, scheduling irrigation under fixed timer-based systems may be inaccurate and costly and, considering these issues, there is a need for a more efficient method.

The use of soil water sensors to control automated irrigation systems is proposed as a useful alternative. However, sensor-based irrigation systems are not widely used in South African nurseries. This may be due to perceived (i) high start-up costs, too expensive to adopt on a large 


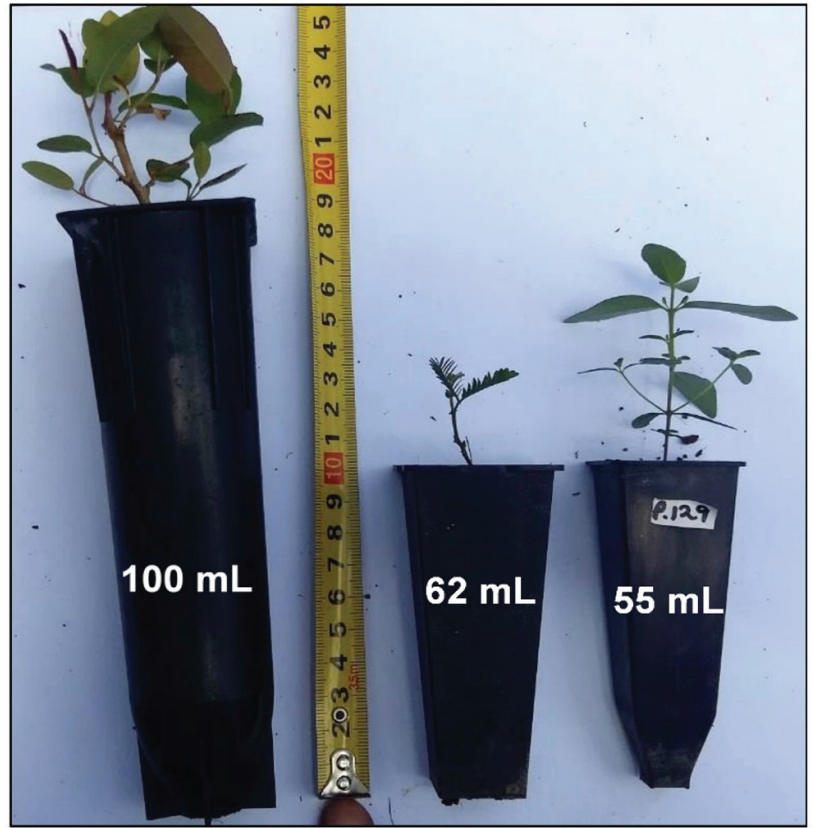

Figure 1. Examples of different sizes of small containers used in many commercial forestry nurseries showing their associated volumes

scale; (ii) difficulty in automation; and (iii) low reliability and maintenance issues (Annandale et al., 2011; Lea-Cox, 2012; Belayneh et al., 2013). For most commercial nurseries, the initial cost and the ease of use are the most crucial considerations for adopting a sensor-based irrigation system. Regardless of these challenges, numerous sensors with the potential to be adapted for use in nursery substrates are well documented in the literature (Burnett and Van Iersel, 2008; Chappell et al., 2013; Bayer et al., 2015; Montesano et al., 2016; Saasvoss et al., 2016; Wheeler et al., 2017). Increasing freshwater scarcity, and pressure from governments, society, and concerned bodies to conserve water, gives motive to investigate sensor-based irrigation systems. Thus, the aim of this review was to evaluate commercially available soil water sensors that can be connected to an automated irrigation system to measure and control water status in small-volume nursery containers to improve nursery water management.

\section{SCHEDULING IRRIGATION IN SMALL-VOLUME CONTAINERS}

Soilless substrates, as used in many commercial nurseries, are generally porous and have relatively large particle sizes compared to mineral soils. They tend to release more water at very low matric potential ( -1 to $-40 \mathrm{kPa})$, which is 10 to 100 times lower than the matric potential in mineral soils (LeaCox et al., 2011). Also, the rooting system of a nursery plant is confined to the volume of the container. For these reasons, maintaining optimal water status for soilless substrates is critical for continued plant growth. A sensor-based system for scheduling irrigation is a logical choice, and consists of sensors linked to an automated irrigation system that periodically measure the substrate water status at a specified interval (Nemali and Van Iersel, 2006; Van Iersel et al., 2013; Lea-Cox et al., 2017; Kaptein et al., 2019). Since water use by the seedling, along with drainage and evaporation, causes a decrease in substrate water level over time, the sensors detect these changes in the substrate volumetric water content $\left(\mathrm{VWC}, \mathrm{m}^{3} \cdot \mathrm{m}^{-3}\right)$ or soil water potential $(\Psi, \mathrm{kPa})$, and relay that information to an irrigation controller (Fig. 2). The irrigation controller is programmed to control (open) selected irrigation valves for irrigation when the water level decreases below a set point (Belayneh et al., 2013; Van Iersel et al., 2013; Bayer et al., 2015; Wheeler et al., 2017). The irrigation is then allowed to continue until the upper set point of the programme is reached, at which time the irrigation valves are closed (Fig. 2).

Irrigation in small containers may be scheduled using two properties, VWC or soil water potential, as described in detail by Jones $(2004 ; 2008)$. The VWC indicates the quantity of water available per unit volume of medium, which is easy to measure and control as long as the lower limit (LL) and drained upper limit (DUL) thresholds are defined (Smith

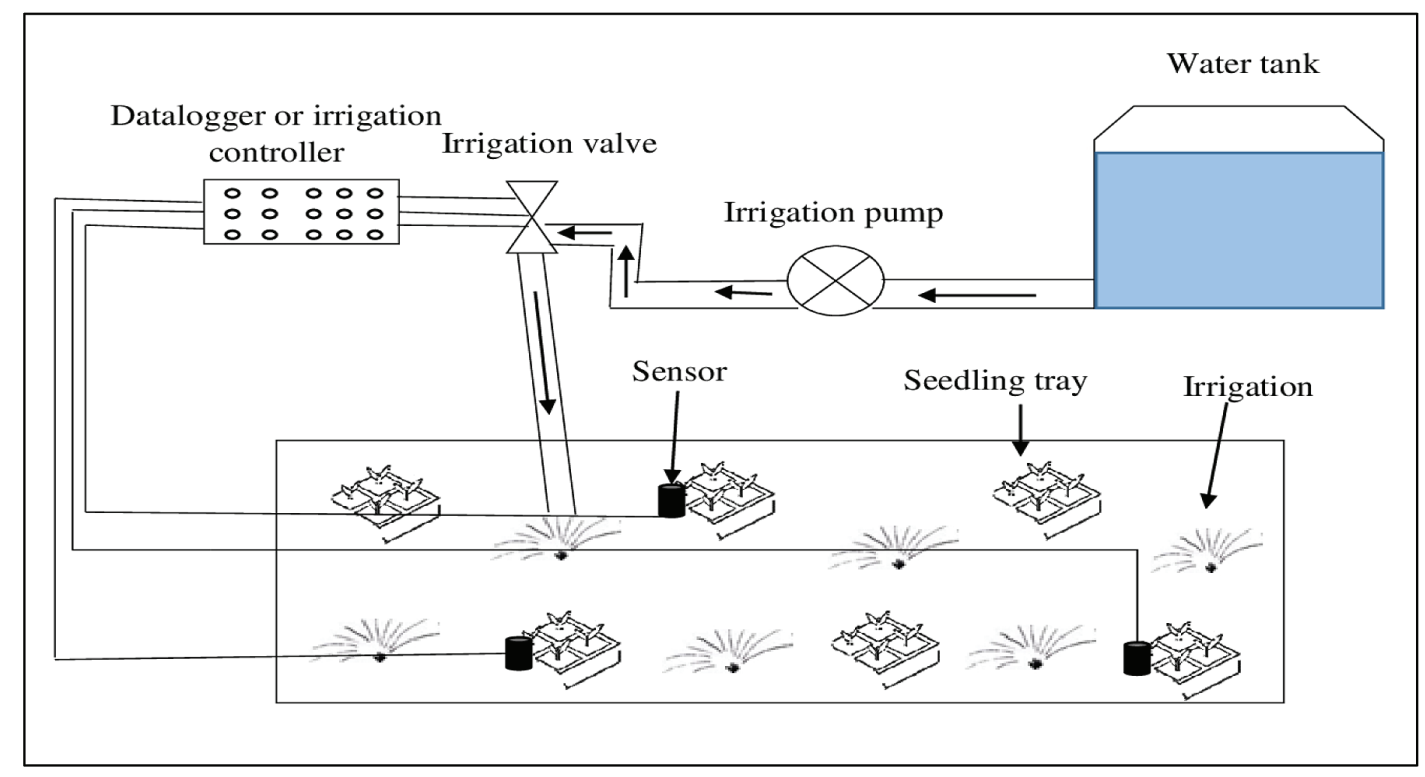

Figure 2. An automated irrigation system capable of measuring the water content of the substrate in the small-volume nursery containers, and controlling the opening and closing of irrigation valves according to lower and upper set points 
and Mullins, 2000; Jones, 2004; Lal and Shuckla, 2004; Gebregiorgis and Savage, 2006). In contrast, the soil water potential is the energy status of water per unit volume of medium, which directly determines whether the substrate water is available to plants (Scanlon et al., 2002; Jones, 2004; Bittelli, 2010; Lea-Cox et al., 2011). Both are related to each other, but this relationship is different for different substrates and depends on pore size distribution (Gebregiorgis and Savage, 2006; Van Iersel et al., 2013). For example, substrates with larger pores hold less water compared to substrates with small pores. This relationship can be determined using a hydraulic conductivity relationship (Van Iersel et al., 2013; Schindler et al., 2016). There is no consensus as to which property is better suited for scheduling irrigation between the two (Van Iersel et al., 2013), although VWC is relatively easy to measure (Jones, 2004). If VWC is used, matric potential should also be estimated using hydraulic conductivity to determine the plant available water. This is critical in highly porous substrates such as pine bark due to its lower buffering capacity. Various VWC and soil water potential sensors that may be used in small-volume containers, and easily connected to a programmable control unit, will be discussed.

\section{VOLUMETRIC WATER CONTENT MEASUREMENT SENSORS}

The main aim of measuring VWC is to monitor water status as it diminishes and recharges within the root zone after each irrigation event (Charlesworth, 2005). The commercially available soil water content sensors do not measure soil water content directly; instead they detect changes in other soil properties that can be related to the soil water content (Charlesworth, 2005; Bittelli, 2010; 2011). The most common soil properties that change with soil water content and are easy to measure include (i) dielectric permittivity (Van Iersel et al., 2013); and (ii) thermal conductivity (Song et al., 1998). However, for accurate measurement, sensors need to be calibrated against the gravimetric method, which is the only direct soil water content measure (Smith and Mullins, 2000; Charlesworth, 2005).

\section{Dielectric sensors}

The term 'dielectric' refers to the ability of a substance to store charge from an electromagnetic field (Evett and Parkin, 2005; Van Iersel et al., 2013). These sensors use an electromagnetic technique to determine the VWC, since water has a much higher dielectric permittivity relative to other constituents of the substrate (Smith and Mullins, 2000; Bogena et al., 2007; Bittelli, 2010). The main components of a substrate that affect the dielectric permittivity are air, solid matrix and water content. The dielectric permittivity of air and a solid matrix is 1 and 5, respectively, compared to that of water which is 80 at $20^{\circ} \mathrm{C}$ (Czarnomski et al., 2005; Bogena et al., 2007; Nemali et al., 2007). Hence, a small change in VWC can result in a significant change in the dielectric permittivity (Nemali et al., 2007; Van Iersel et al., 2013). Thus, the measurement of dielectric permittivity can be used to indirectly estimate the media VWC through predetermined calibration relationships using the equation of Topp et al. (1980). For this review, frequency domain reflectometry (FDR) and time domain reflectometry (TDR) sensors will be further discussed due to their suitability for use in small-volume nursery containers.

\section{Frequency domain reflectometry}

Most FDR sensors (also referred to as capacitance sensors) consist of two prongs (positive and negative electrodes) that produce an electromagnetic field (Bittelli, 2010) when placed parallel to each other (as shown in Fig. 3). The electromagnetic field is passed through dielectric material and then its ability to store charge is measured. The charge stored by the substrate and measured by a capacitor is directly related to the dielectric permittivity of a substrate (Bogena et al., 2007). The sensor circuitry then converts the capacitor charge to a voltage, so it can be measured using a control unit. Since water molecules store charge more than other particles in the substrate, this charge storing ability can be related to VWC through measurement of charge time $t$ (s) using:

$$
t=-R C \ln \left\lfloor\left(V-V_{f}+V_{i}\right) /\left(V_{i}-V_{f}\right)\right\rfloor
$$

where $R(\Omega)$ is the series resistance, $C(\mu \mathrm{F})$ the capacitance, $V$ (V) the supply voltage, $V_{i}$ the initial voltage and $V_{f}$ the final voltage (Charlesworth, 2005).

When the VWC is high, the capacitor will charge slowly. This means that the capacitor of a sensor embedded in a wet substrate will reach a given voltage threshold later compared to a capacitor in a dry substrate. More specifications, advantages and disadvantages of FDR sensors are provided in Table 1.

The FDR sensors are laboratory-calibrated by the manufacturer in different soilless substrates to produce a generic equation. The factory generic calibration equation has an accuracy range of $0.03-0.05 \mathrm{~m}^{3} \cdot \mathrm{m}^{-3}$ (Meter Group, 2018a, 2018b). Although a generic equation may be used with reasonable accuracy, a substrate-specific calibration may be conducted to estimate VWC to within $0.01 \mathrm{~m}^{3} \cdot \mathrm{m}^{-3}$ of the actual VWC. For substrate-specific calibration, a single calibration equation could be used for a similar model FDR sensor regardless of the substrate type (organic or inorganic) (Nemali et al., 2007). Some of these sensors consist of additional sensors that measure soil temperature and electrical conductivity (EC) within the FDR sensor (Meter Group, 2018a, 2018b). These sensors have been used successfully to schedule irrigation in several studies with highly porous soilless substrates in nursery containers (Burnett and Van Iersel, 2008; Van Iersel et al., 2010; Belayneh et al., 2013; Bayer et al., 2015; Montesano et al.,

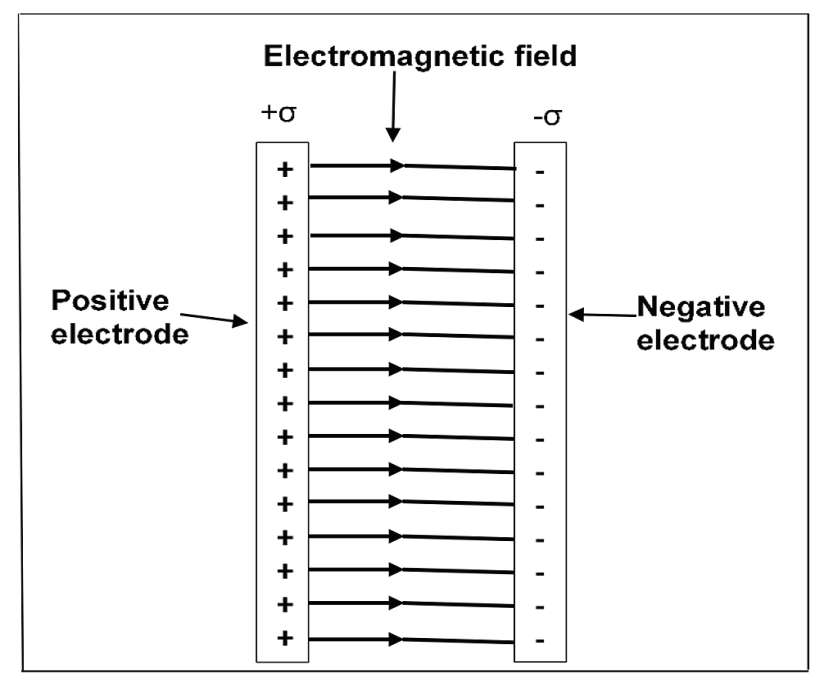

Figure 3. An electromagnetic field formed with a frequency domain reflectometry sensor (source: Campbell, 2012) 
2016; Wheeler et al., 2017; Kaptein et al., 2019). Improvements in plant growth, reduction in water usage, and fewer incidences of pests and diseases were reported.

\section{Time domain reflectometry}

The TDR technology was initially used to find the break in power lines. Instead of manually inspecting a power line, a pulse is sent along the cable, and the time taken for the pulse to reflect indicates the precise point where the cable is broken. A TDR sensor works similarly by sending electromagnetic waves from the pulse generator of a cable tester to diffuse in the substrate where there is a parallel pair transmission line (Topp et al., 1984; Nobori, 1996). Electromagnetic waves are diffused through a coaxial cable to a probe inserted in a substrate. Some of these electromagnetic waves are reflected at the beginning of the probe due to impedance differences between the cable and the probe, whereas the rest of the waves diffuse through the probe until they reach the end of the probe where they are reflected (Noborio et al., 1996). Therefore, dielectric permittivity can be calculated considering that the transmission velocity is determined from the known length of the transmission line in the substrate using (Topp et al., 1984):

$$
K_{a}=c t / l
$$

where $K_{a}$ is the soil dielectric constant, $c$ the velocity of an electromagnetic signal in free space (i.e. speed of light, $3 \times 10^{8}$ $\left.\mathrm{m} \cdot \mathrm{s}^{-1}\right), t$ the travel time of the voltage pulse and $l$ the length of the soil transmission line $(\mathrm{mm})$. Since substrate water content is the main factor that alters the dielectric permittivity $\left(K_{e}\right)$, VWC can be calculated using (Topp et al., 1980):

$$
\mathrm{VWC}=-5.3 \times 10^{-2}+2.92 \times 10^{-2} K_{a}-5.5 \times 10^{-4} K_{a}^{2}+4.3 \times 10^{-6} K_{a}^{3}
$$

The specifications, advantages and disadvantages of TDR sensors are further outlined in Table 1.

\section{Influence of substrate properties on dielectric permittivity}

The dielectric permittivity may be influenced by factors other than the VWC (Smith and Mullins, 2000; Lukanu and Savage, 2006). Studies have indicated that dielectric sensors may be affected by the substrate temperature and EC (Scanlon et al., 2002; Bogena et al., 2007; Bittelli, 2010; 2011). However, the new generation of VWC sensors have a built-in temperature sensor that corrects for error in VWC estimation due to temperature changes, for example, a model 5TM or TEROS 10 (Meter Group, Inc., Pullman, WA, USA).

In a nursery, most substrates used as potting media are a unique blend of organic and inorganic materials, and seedlings are frequently irrigated with water-soluble fertilisers. This can result in an increased concentration of ions of fertiliser salts near the electromagnetic field of a dielectric probe which could weaken the electromagnetic energy and affect the measured VWC (Nemali et al., 2007; Rosenbaum et al., 2010). In a study by Kizito et al. (2008), a measurement frequency of $70 \mathrm{MHz}$ mitigated the effects of EC and temperature on FDR sensors (model EC-5 and $\mathrm{ECH}_{2} \mathrm{O}-\mathrm{TE}$, Meter Group). Latest FDR sensors measure dielectric permittivity using an oscillator operating at a frequency of $70 \mathrm{MHz}$ making this sensor insensitive to EC below $10 \mathrm{dS} \cdot \mathrm{m}^{-1}$ (Meter Group, 2018a, 2018b). To be able to measure in substrates with EC greater than $10 \mathrm{dS} \cdot \mathrm{m}^{-1}$, substrate-specific calibration is a necessity, although such high EC is extremely uncommon in nursery substrates since it will most likely cause root death in most plant species. Increasing measurement frequency to higher frequencies (i.e. $150 \mathrm{MHz}$ ) decreases the sensor sensitivity to EC considerably; however, this increases sensor cost due to the increase in sensor electronics.

The effect of poor substrate-to-sensor contact caused by uneven packing of substrate in containers has been reported by Bogena et al. (2007), Nemali et al. (2007) and Van Iersel et al. (2010). This may be critical in some nurseries where the substrate is manually packed in small-volume containers

\begin{tabular}{|c|c|c|c|}
\hline & $\begin{array}{l}\text { Frequency domain } \\
\text { reflectometry (Capacitance) }\end{array}$ & $\begin{array}{l}\text { Time domain } \\
\text { reflectometry }\end{array}$ & $\begin{array}{l}\text { Dual needle } \\
\text { heat pulse }\end{array}$ \\
\hline $\begin{array}{l}\text { Cost (amounts as at Nov 2018: } \\
1 \text { USD }=14.30 \text { ZAR) per sensor }\end{array}$ & $2200-3550$ ZAR & $2860 Z A R$ & 3490 ZAR \\
\hline Accuracy $\left(\mathrm{m}^{3} \cdot \mathrm{m}^{-3}\right)$ & $0.01-0.03$ & $0.02-0.05$ & 0.05 \\
\hline Measurement range (\%) & $0-100$ & $0-100$ & $0-100$ \\
\hline Measurement volume (mL) & $240-715$ & 100 & 50 \\
\hline Examples (model) & EC-5 ${ }^{\mathrm{a}}, 5 \mathrm{TM}^{\mathrm{a}}, \mathrm{GS} 1^{\mathrm{a}}$, TEROS $10^{\mathrm{a}}$ & T-3 (T3R/F; mini-TDR) $)^{b}$ & Specific heat capacity sensor ${ }^{b}$ \\
\hline Advantages & $\begin{array}{l}\text { No calibration needed ( } 3 \% \text { VWC } \\
\text { accuracy) } \\
\text { Insensitive to salinity } \\
\text { Simple readout device } \\
\text { Inexpensive } \\
\text { Low power usage } \\
\text { Easy to install }\end{array}$ & $\begin{array}{l}\text { No calibration needed } \\
\text { Less sensitive to salinity }<3 \mathrm{dS} \cdot \mathrm{m}^{-1}\end{array}$ & $\begin{array}{l}\text { Compact size } \\
\text { No calibration needed }\end{array}$ \\
\hline Disadvantages & $\begin{array}{l}\text { Sensitive to air gaps } \\
\text { Need substrate-specific calibration } \\
\text { for improved accuracy ( } 1 \% \text { VWC } \\
\text { accuracy) }\end{array}$ & $\begin{array}{l}\text { Expensive when pulse is included } \\
\text { Their complexity requires } \\
\text { expertise to set-up } \\
\text { High power usage }\end{array}$ & $\begin{array}{l}\text { Fragile } \\
\text { Susceptible to substrate } \\
\text { temperature gradients } \\
\text { Needle deflection can impart } \\
\text { high error ( } 1 \mathrm{~mm} \text { deflection = } \\
6 \% \text { error) } \\
\text { Must be connected to good } \\
\text { dataloggers }\end{array}$ \\
\hline
\end{tabular}

Table 1. Summary of techniques used to measure substrate water content (adapted from Jones, 2004)

${ }^{a}$ Meter Group, Inc., Pullman, WA, USA ${ }^{b}$ East 30 Sensors, Pullman, WA, USA 
which may lead to a lack of solid contact between the sensor and the substrate causing inaccurate measurements of VWC. According to Lukanu and Savage (2006), differences in bulk density can have a small effect on FDR sensor measurements although VWC can be measured to within $0.02 \mathrm{~m}^{3} \cdot \mathrm{m}^{-3}$. Van Iersel et al. (2013) reported that measurement errors due to air spaces can be improved by frequent irrigation schedules until substrate particles settle around the sensor.

\section{Dual needle heat pulse sensors}

The dual needle heat pulse (DNHP) method was first suggested by Campbell et al. (1991) and has since been used by several researchers (Tarara and Ham, 1997; Song et al., 1998; Ochsner et al., 2003). This technique measures changes in soil thermal properties (Song et al., 1998; Bittelli, 2010; 2011) caused by the variation in the VWC. Tarara and Ham (1997) describe the technique in detail, and Fig. 4 shows a probe with needle length of $30 \mathrm{~mm}$. A heater and a temperature probe (usually a thermocouple) are used to determine the substrate volumetric heat capacity, which can be converted into VWC using:

$$
V W C=\left[q /\left(e \pi r^{2} \Delta T_{m}-\left(19.92 x_{m}+2.51\right)\right] / 4.18\right.
$$

where $q\left(\mathrm{~J} \cdot \mathrm{m}^{-1}\right)$ is the heat applied per unit length of the line source, $e$ is the natural logarithm base, $r(\mathrm{~m})$ is the distance between the heater probe and temperature probe, $\Delta T_{m}$ is the maximum temperature increase of the needle $\left({ }^{\circ} \mathrm{C}\right)$ and $x_{m}$ is determined by dividing the substrate bulk density by particle size (Song et al., 1998).

The small compact size of the DNHP sensor enables measurements of small substrate volumes such as water content around a growing seed (Tarara and Ham, 1997). Bristow et al. (1993) compared the VWC as measured using DNHP sensors versus the VWC measured by gamma attenuation in repacked soil in the laboratory. The DNHP sensors estimated VWC to within $0.04 \mathrm{~m}^{3} \cdot \mathrm{m}^{-3}$ of the gamma attenuation method at both the LL and DUL. However, large differences between VWC measured with DNHP sensors versus using the gravimetric method were observed by Tarara and Ham (1997) at high water content. At water contents less than $0.30 \mathrm{~m}^{3} \cdot \mathrm{m}^{-3}$, the DNHP probe estimates were within $0.06 \mathrm{~m}^{3} \cdot \mathrm{m}^{-3}$ of the gravimetric method. The probes of this sensor type are very fragile and special care needs to be taken so that the distance between the needle probes does not alter (Campbell et al., 1991; Bittelli, 2010). A needle deflection of $1 \mathrm{~mm}$ may cause a $6 \%$ error in VWC measurements (Song et al., 1998; Scanlon et al., 2002). The conversion of a temperature signal from analogue to digital may cause a measurement error in $\Delta T_{m}$ (Bristow et al., 1993;

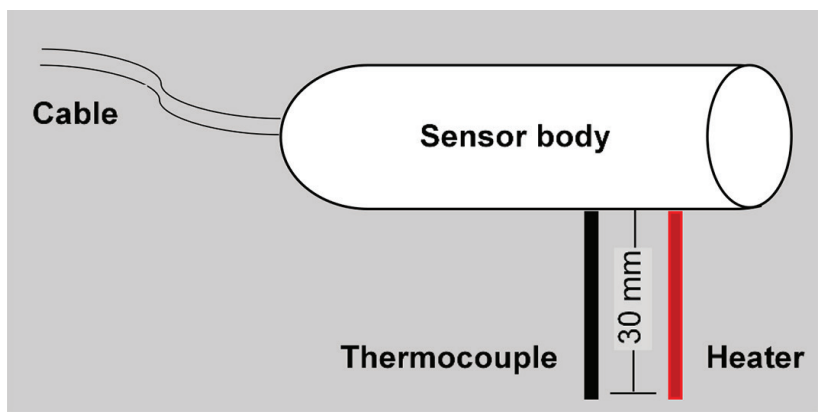

Figure 4. A dual needle heat pulse probe (adapted from: Tarara and Ham, 1997)
Song et al., 1998). This, however, can be minimised by increasing the datalogger sampling frequency by using a high resolution datalogger and applying sufficient power to the heater probe so that $\Delta T_{m}$ exceeds $0.5^{\circ} \mathrm{C}$. This sensor is also susceptible to substrate temperature gradients (Scanlon et al., 2002), which may be significant in a nursery environment, and therefore precise substrate temperature measurements are needed. For these reasons, this type of sensor should be used with caution in scheduling nursery irrigation, and, in most cases, is not practical.

\section{MEASURING THE SUBSTRATE WATER POTENTIAL}

The concept of soil water potential is not new. As early as 1908 , the first attempts to measure soil water potential were conducted using the Livingston disc (Crawford, 2015). A dry ceramic disc would be weighed, then placed in soil so that it equilibrated with the surroundings. After equilibration, it was removed, cleaned and weighed again. Soil water potential was then calculated using the water retention curve of the disc. Over 100 years later, there have been many advances in soil water potential sensor technology, but these sensors still rely on water potential equilibration. Most commercially available soil water potential sensors accurately measure within the 0 to -100 $\mathrm{kPa}$ range, which is ideal for most nursery crops since they generally exhibit signs of water stress at matric potential less than $-100 \mathrm{kPa}$. Different techniques for measuring soil water potential in small-volume seedling containers are examined and summarised in Table 2.

\section{Tensiometers}

In 1960, a liquid calibration technique called tensiometry was discovered (Charlesworth, 2005). This method, along with soil psychrometry, was and still is the only direct method of measuring soil water potential. If correctly installed, a tensiometer is the most accurate soil water potential sensor in wet substrate (0 to $-90 \mathrm{kPa}$ ) (Charlesworth, 2005; Bittelli, 2010). For an in-depth understanding of tensiometer measurement theory, see Smith and Mullins (2000) and Bittelli (2010). The advantages and disadvantages of tensiometers are outlined in Table 2. Small tensiometers fitted with transducers to measure and control the water potential in small-volume soilless substrates were reported by Bittelli (2010). A schematic diagram of such a tensiometer is shown in Fig. 5, with a diameter of $5 \mathrm{~mm}$ for an easy fit in a small-volume container. The transducer is used to convert the tensiometer tension to an electrical signal that may be sensed by a control unit.

When tensiometers are used, precautionary measures are necessary to ensure direct contact between the porous ceramic tensiometer tip and the substrate, and correct positioning of the sensor. If the substrate shrinks, or the tensiometer is disturbed, this contact may be interrupted after which air may enter and break the water column resulting in inaccurate measurements. In soilless substrates, fine roots might develop around the ceramic tip. This is common when the substrate dries out and the ceramic tip becomes an unreliable but assured water source (Meter Group, 2009). When the substrate becomes drier than $-90 \mathrm{kPa}$, cavitation occurs, where liquid water pressure inside the tensiometer tube changes to water vapour pressure causing spontaneous evaporation and formation of air bubbles as described by Bittelli (2010). However, the new commercially available tensiometers can measure up to $-500 \mathrm{kPa}$ without cavitation, for example, a model T5x mini tensiometer (Meter Group). This is made 


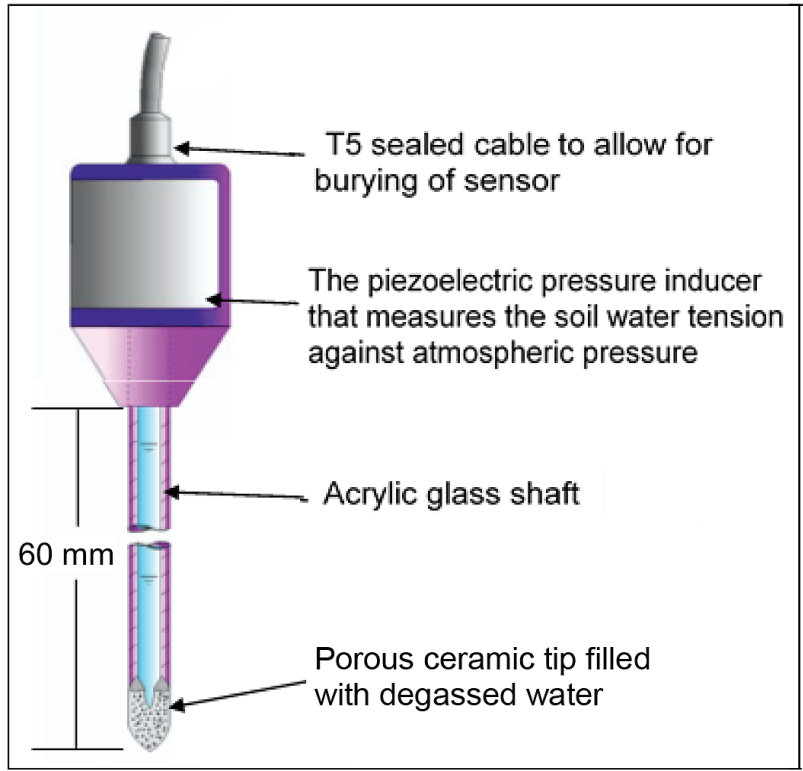

Figure 5. A transducer fitted mini tensiometer (Meter Group model T-5 laboratory tensiometer) (Source: Meter Group)

possible using a special ceramic tip with smaller pores and a gas-free filling. Van der Ploeg et al. (2010) also investigated polymer tensiometers that are not affected by cavitation and have an extended measurement range to $-2000 \mathrm{kPa}$. These tensiometers consist of a swelling polymer that creates a positive pressure, and when the substrate is wet it absorbs water, creating a pressure offset. These tensiometers are, however, not yet well researched for use in nursery soilless substrates. Charlesworth (2005) reported on equitensiometers that use the principle of dielectric sensors to measure the water potential. These sensors do not require substrate-specific calibration since they measure the water potential of the ceramic material and not the surrounding substrate.

\section{Heat dissipation sensors}

As early as 1940, Shaw and Baver (1940) proved that soil water

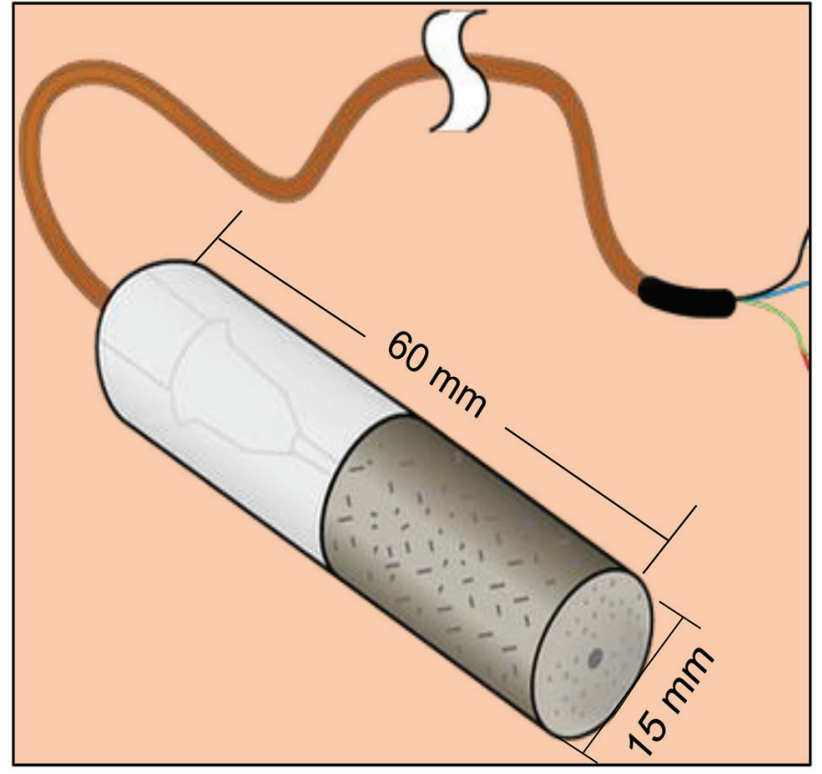

Figure 6. A heat dissipation sensor (Campbell Scientific, model 229-L) (Source: Campbell Scientific, 2009)

potential could be inferred from the rate of heat dissipated in the soil, and many sensors have been developed based on this relationship. Flint et al. (2002) described heat dissipation probe measurement theory in detail and a sensor is shown in Fig. 6. The sensor has a ceramic cup which equilibrates with the substrate. Following equilibration, a heating element is heated for a specific period, and a change in the substrate temperature is then measured. The temperature change depends on the thermal conductivity of the ceramic cup, which is affected by the VWC of the substrate (Flint et al., 2002; Scanlon et al., 2002; Bittelli, 2010). Thus, the VWC, which is related to the water potential of the ceramic cup, can be determined through a hydraulic conductivity relationship. The commonly used function is:

$$
\Psi=\exp (\alpha \Delta T+\beta)
$$

where $\Psi$ is the soil water potential, exp the exponential function, $\Delta T$ the increase in temperature for specified period of time, $\alpha$ the

Table 2. Summary of techniques used to measure substrate matric potential (adapted from Jones, 2004)

\begin{tabular}{|c|c|c|c|}
\hline & Water potential & Tensiometers & Heat dissipation \\
\hline $\begin{array}{l}\text { Cost (amounts as at Nov 2018: } \\
1 \text { USD }=14.30 \text { ZAR) per sensor }\end{array}$ & 4150 ZAR & 11390 ZAR & 7000 ZAR \\
\hline Accuracy $(\mathrm{kPa})$ & \pm 2 below -100 & \pm 0.5 & $3-5$ \\
\hline Measurement range $(\mathrm{kPa})$ & -100000 to -9 & -500 to 0 & -2500 to -10 \\
\hline Equilibration time & $10 \mathrm{~min}$ to $1 \mathrm{~h}$ & $5 \mathrm{~s}$ & $1 \mathrm{~h}$ \\
\hline Measurement volume $(\mathrm{mL})$ & 1 & $>100$ & 1 \\
\hline Examples (model) & TEROS $21^{\mathrm{a}}$ & $T-5 x^{a}$ & $229-\mathrm{L}^{\mathrm{b}}$ \\
\hline Advantages & $\begin{array}{l}\text { Moderate to good accuracy } \\
\text { Wide measurement range } \\
\text { Insensitive to salinity below } \\
10 \mathrm{dS} \cdot \mathrm{m}^{-1} \\
\text { Different sizes available }\end{array}$ & $\begin{array}{l}\text { Direct measure } \\
\text { Excellent accuracy between } \\
-90 \text { to } 0 \mathrm{kPa}\end{array}$ & $\begin{array}{l}\text { No maintenance needed } \\
\text { Insensitive to salinity } \\
\text { Moderate to good accuracy }\end{array}$ \\
\hline Disadvantages & $\begin{array}{l}\text { Air entry in ceramic discs limit } \\
\text { accuracy } \\
\text { Sensitive to air gaps } \\
\text { Low accuracy between }-100 \text { and } 0 \\
\text { kPa }\end{array}$ & $\begin{array}{l}\text { Need re-filling with degassed } \\
\text { water after dry periods } \\
\text { Air entry in ceramic tip limit upper } \\
\text { range measurements } \\
\text { High maintenance requirements in } \\
\text { porous substrates }\end{array}$ & $\begin{array}{l}\text { Need complex heating } \\
\text { controller } \\
\text { Slow reaction time } \\
\text { High power usage } \\
\text { High variability between } \\
\text { sensors }\end{array}$ \\
\hline
\end{tabular}

${ }^{a}$ Meter Group, Inc., Pullman, WA, USA ${ }^{b}$ Campbell Scientific, Inc., Logan, Utah, USA 
slope and $\beta$ the intercept (Campbell Scientific, 2009). The relationship between the natural logarithm of soil water potential and temperature increase is linear (Campbell Scientific, 2009). The heat transfer properties between the heater and the ceramic cup of the sensor vary vastly between sensors, thus necessitating individual sensor calibration (Flint et al., 2002; Scanlon et al., 2002). These sensors can be used for scheduling irrigation in a laboratory and in greenhouses. However, due to their complexity, their use has been limited to research applications.

\section{IDEAL SENSORS FOR USE WITH A NURSERY AUTOMATED IRRIGATION SYSTEM}

The first step in selecting a sensor to use with an irrigation system is to identify the substrate property to measure, either VWC or water potential. There are a variety of commercially available sensors that may be used to measure either of these properties, as described previously. Soil water potential sensors should, however, be used with caution in small volume nursery containers. Several studies have indicated that these sensors are less accurate at low soil water potentials $(<-30 \mathrm{kPa})$, which is when most seedlings show signs of water stress. Minitensiometers require high maintenance and are also less reliable in automated irrigation systems.

An ideal sensor should provide high accuracy and resolution, enable rapid and precise measurements, be easy to install, allow for custom calibration, have a long life expectancy, and be cost effective (Gebregiorgis and Savage, 2006; Jones, 2008). Cost (both purchase and maintenance), life expectancy, ease of use and media-specific calibration are key aspects to the adoption and use of sensor-based automated irrigation by nursery managers (Lea-Cox, 2012).

\section{Cost-effectiveness}

A typical seedling nursery consists of different seedling types at different ages. For example, a forestry nursery may have different seedling clones ranging from 1-day-old to 3-months-old. To control irrigation, multiple sensors may be required for different irrigation zones. In this case, many inexpensive sensors may be an option. In addition, multiple sensors may be needed to improve the quality of collected data. As an example, low-cost FDR sensors (model EC-5, Meter Group) have been successfully used in soilless substrates by Montesano et al. (2016), Saavoss et al. (2016), Wheeler et al. (2017) and Kaptein et al. (2019) due to their cost-effectiveness and ease of use. The challenge is selecting trade-offs between various sensor properties. For example, durable high-accuracy sensors with good precision and resolution may be more expensive than less durable loweraccuracy sensors. Sensor manufacturers may attempt to find the balance between these properties, but to select the best sensor for an application, it is important to ensure that minimum requirements for a particular purpose are met (Lea-Cox, 2012; Van Iersel et al., 2013). It may be necessary for a sensor used in a research study to have high accuracy, good precision and resolution, whereas a sensor used for scheduling irrigation may not necessarily need to have the same level of accuracy, as long as measurements are repeatable with good resolution and precision.

\section{Specific media calibration}

Most sensors are supplied with a generic calibration equation. However, not all soilless substrates used in nurseries have identical electrical properties due to variations in bulk density and salinity. Thus, the generic calibration may result in an approximately $5 \%$ error in VWC estimation, whereas a substrate-specific calibration can reduce this error to $1 \%$. Furthermore, different soilless substrates have different water-holding capabilities (Van Iersel et al., 2013), and it is important to understand the relationship between VWC and plant available water for different substrates. For example, a $20 \%$ VWC measurement in sand indicates a moist to saturated substrate and much of this water is available to seedlings. Irrigating this substrate further will simply result in excess water drainage. However, a value of $20 \%$ in coir indicates a much drier medium, meaning there is little or no plant available water in the substrate (Van Iersel et al., 2013).

Manufacturers commonly calibrate their sensors in the laboratory with minimal variation in environmental factors, in particular temperature. When the sensor is in a natural environment and exposed to more environmental variation, its accuracy may not meet the specified manufacturer specifications (Van Iersel et al., 2013). The effect of temperature is more pronounced in sensors such as DNHP and TDR. However, most of the new model commercially available sensors have a built-in temperature and EC sensor to correct for substrate temperature effects. Although media-specific calibration improves VWC measurement accuracy, generic calibration could be used for irrigation scheduling purposes with slightly less accuracy (Kaptein et al., 2019). Sensor-tosensor variability has been shown to be relatively low within soilless substrates, even with influencing factors such as air gaps and bulk density (Belayneh et al., 2013; Kaptein et al., 2019). Also, it is beneficial to install several sensors and use their average output for scheduling irrigation decisions.

All sensors have measurement errors and there is no one sensor that is ideal. The best sensor for an application is the one that measures what the end-user needs. There are a variety of good commercially available sensors, and if the user understands what the sensor measures, then it becomes easier to compare and make the best choice for the application. Also, most sensors can be integrated into an existing nursery irrigation system, ensuring economic feasibility. For small-volume soil water measurements in nursery applications, sensor size and substrateto-sensor contact are the most important considerations in this environment in which large temperature gradients may occur. This then limits sensor choice to a few capacitance sensors.

\section{Potential economic impact}

The use of a sensor-based automated irrigation system may have a positive impact within a nursery in different ways, such as improved water use efficiency, reduction in water and energy costs, labour savings, improved crop quality and shorter crop production cycles, as reported in detail by Belayneh et al. (2013). A reduction in irrigation water usage by $40-70 \%$ was reported by Bayer et al. (2013) and Chappell et al. (2013). This resulted in reduction in leaching of nutrients, thereby reducing the nursery fertiliser costs by $50 \%$. Overall, in a study by Saavoss et al. (2016) a sensor-based irrigation system showed an increase in nursery annual profits by $156 \%$ compared to a standard timer-based system. This profit was mainly attributed to improved plant growth, improved crop quality and shorter production cycles.

\section{CONCLUSIONS}

In this review, different techniques for measuring VWC and water potential that are appropriate for use in small-volume 
nursery containers were described. Many researchers have concluded that the sensor-based irrigation systems are more efficient and effective compared to timer-based systems. Also, the quality of seedlings produced using a sensorbased irrigation system is generally better than that from conventional timer systems. To select an optimal sensor for use in small-volume seedling containers, sensor cost-effectiveness and the ability to calibrate against the gravimetric method should be prioritised. Moreover, the sensor should meet the minimum requirements for an application. Utilising sensorbased irrigation systems may benefit the commercial nursery industry and reduce the high water consumption, thereby improving overall water management.

\section{ACKNOWLEDGEMENTS}

Funding from the Institute for Commercial Forestry Research (ICFR) is gratefully acknowledged. Many thanks also go to Professor Colin Dyer and Dr Andrew Morris of the ICFR for supporting this research. Dr Louis Titshall and Dr Steven Dovey are thanked for their constructive input.

\section{REFERENCES}

ANNANDALE JG, STIRZAKER RJ, SINGELS A, VAN DER LAAN $M$ and LAKER MC (2011) Irrigation scheduling research: South African experiences and future prospects. Water SA 37 751-764. https://doi.org/10.4314/wsa.v37i5.12

BAYER A, RUTER J and VAN IERSEL MW (2015) Automated irrigation control for improved growth and quality of Gardenia jasminoides 'Radicans' and 'August Beauty'. HortScience 50 78-84.

BAYER A, WHITAKER K, CHAPPELL M, RUTER J and VAN IERSEL M (2013) Effect of irrigation duration and fertilizer rate on plant growth, substrate solution EC, and leaching volume. Acta Hortic. 1034 477-484. https://doi.org/10.17660/ActaHortic.2014.1034.59

BELAYNEH BE, LEA-COX JD and LICHTENBERG E (2013) Costs and benefits of implementing sensor-controlled irrigation in a commercial pot-in-pot container nursery. HortTechnology 23 760-769.

BITTELLI M (2010) Measuring soil water potential for water management in agriculture: A review. Sustainability 2 1226-1251. https://doi.org/10.3390/su2051226

BITTELLI M (2011) Measuring soil water content: A review. HortTechnology 21 293-300.

BOGENA HR, HUISMAN JA, OBERDÖRSTER C and VEREECKEN $\mathrm{H}$ (2007) Evaluation of a low-cost soil water content sensor for wireless network applications. J. Hydrol. 344 32-42. https://doi. org/10.1016/j.jhydrol.2007.06.032

BRISTOW KL, CAMPBELL GS and CALISSENDORFF K (1993) Test of a heat-pulse probe for measuring changes in soil water content. Soil Sci. Soc. Am. J. 57 930-934. https://doi.org/10.2136/ sssaj1993.03615995005700040008x

BURNETT SE and VAN IERSEL M (2008) Morphology and irrigation efficiency of Gaura lindeheimeri grown with capacitance sensorcontrolled irrigation. HortScience 43 1555-1560.

CAMPBELL GS, CALISSENDORFF C and WILLIAMS JH (1991) Probe for measuring soil specific heat using a heat-pulse method. Soil Sci. Soc. Am. J. 55 291-293. https://doi.org/10.2136/ sssaj1991.03615995005500010052x

CAMPBELL SCIENTIFIC (2009) 229 Heat dissipation matric water potential sensor manual. URL: https://s.campbellsci.com/ documents/br/manuals/229.pdf (Accessed 23 October 2018).

CAMPBELL C (2012) Soil moisture 201: Water content measurements, methods, and applications theory and application. URL: https://www. metergroup.com/environment/events/soil-moisture-201-measurementsmethods-and-applications/ (Accessed 1 December 2018).

CHAPPELL M, DOVE SK, VAN IERSEL MW, THOMAS PA and RUTER J (2013) Implementation of wireless sensor networks for irrigation control in three container nurseries. HortTechnology
23 747-753.

CHARLESWORTH P (2005) Soil water monitoring. Irrigation Insights No. 1, Second Edition. URL: http://www.insidecotton.com/xmlui/ bitstream/handle/1/1726/pr000236.pdf (Accessed 17 October 2018).

CRAWFORD L (2015) The history and future of water potential. URL: http://www.environmentalbiophysics.org/the-history-and-futureof-water-potential/ (Accessed 16 August 2014).

CZARNOMSKI NM, MOORE GW, PYPKER TG, LICATA J and BOND BJ (2005) Precision and accuracy of three alternative instruments for measuring soil water content in two forest soils of the Pacific Northwest. Can. J. For. Res. 35 1867-1876. https://doi. org/10.1139/x05-121

DURNER EF (2013) Principles of Horticultural Physiology. CABI Publishers, London. 416 pp.

EVETT SR and PARKIN GW (2005) Advances in soil water content sensing. Vadose Zone J. 4 986-991. https://doi.org/10.2136/ vzj2005.0099

FANADZO M and NCUBE B (2017) Challenges and opportunities for revitalising smallholder irrigation schemes in South Africa. Water SA 44 436-447. https://doi.org/10.4314/wsa.v44i3.11

FLINT AL, CAMPBELL GS, ELLET KM and CALISSENDORFF C (2002) Calibration and temperature correction of heat dissipation matric potential sensors. Soil Sci. Soc. Am. J. 66 1439-1445. https:// doi.org/10.2136/sssaj2002.1439

GEBREGIORGIS MF and SAVAGE MJ (2006) Field, laboratory and estimated soil-water content limits. Water SA 32 155-162. https:// doi.org/10.4314/wsa.v32i2.5256

GLEESON T, ALLEY WM, ALLEN DM, SOPHOCLEOUS MA, ZHOU Y, TANIGUCHI M and VANDERSTEEN J (2012) Towards sustainable groundwater use: Setting long-term goals, backcasting, and managing adaptively. Groundwater 50 19-26. https://doi. org/10.1111/j.1745-6584.2011.00825.x

JONES HG (2004) Irrigation scheduling: advantages and pitfalls of plant-based methods. J. Exp. Bot. 55 2427-2436. https://doi. org/10.1093/jxb/erh213

JONES HG (2008) Irrigation scheduling - comparison of soil, plant and atmosphere monitoring approaches. Acta Hortic. 792 391-403. https://doi.org/10.17660/ActaHortic.2008.792.46

KAPTEIN ND, SAVAGE MJ and LIGHT ME (2019) An irrigation control system with a web-based interface for the management of Eucalyptus planting stock in a nursery. South. For. 81 31-37. https:// doi.org/10.2989/20702620.2018.1479922

KIZITO F, CAMPBELL CS, CAMPBELL GS, COBOS DR, TEARE BL, CARTER B and HOPMANS JW (2008) Frequency, electrical conductivity and temperature analysis of a low-cost capacitance soil moisture sensor. J. Hydrol. 352 367-378. https://doi. org/10.1016/j.jhydrol.2008.01.021

LAL R and SHUCKLA MK (2004) Principles of Soil Physics. Taylor and Francis Library, New York. 736 pp.

LEA-COX JD, ARGUEDAS-RODRIGUEZ FR, RISTVEY AG and ROSS DS (2011) Relating real-time substrate matric potential measurements to plant water use for precision irrigation. Acta Hortic. 891 201-208. https://doi.org/10.17660/ ActaHortic.2011.891.23

LEA-COX JD (2012) Using wireless sensor networks for precision irrigation scheduling. In: Kumar M (ed.) Problems, Perspectives and Challenges of Agricultural Water Management. IntechOpen, Croatia. https://doi.org/10.5772/31236

LEA-COX JD, BELAYNEH BE, MAJSZTRIK J, RISTVEY AG, LICHTENBERG E, VAN IERSEL MW, CHAPPELL M, BAUERLE WL, KANTOR G, KOHANBASH D and co-authors (2017) Demonstrated benefits of using sensor networks for automated irrigation control in nursery and greenhouse production systems. Acta Hortic. 1150 507-514. https://doi.org/10.17660/ ActaHortic.2017.1150.70

LICHTENBERG E, MAJSZTRIK J and SAAVOSS M (2013) Profitability of sensor-based irrigation in greenhouse and nursery crops. HortTechnology 23 770-774.

LUKANU G and SAVAGE MJ (2006) Calibration of a frequencydomain reflectometer for determining soil-water content in a clay loam soil. Water SA 32 37-42.

METER GROUP (2009) User Manual: T5/T5x Pressure Transducer 
Tensiometer. URL: http://library.metergroup.com/Manuals/UMS/ T5_Manual.pdf (Accessed: 20 October 2018).

METER GROUP (2018a) 5TM Manual. URL: http://publications. metergroup.com/Manuals/20424_5TM_Manual_Web.pdf (Accessed 22 October 2018).

METER GROUP (2018b) EC5 Manual. URL: http://publications. metergroup.com/Manuals/20431_EC-5_Manual_Web.pdf (Accessed 22 October 2018).

MONTESANO FF, VAN IERSEL MW and PARENTE A (2016) Timer versus moisture sensor-based irrigation control of soilless lettuce: Effects on yield, quality and water use efficiency. Hortic. Sci. (Prague) 43 67-75. https://doi.org/10.17221/312/2014-HORTSCI

NEMALI KS, MONTESANO F, DOVE SK and VAN IERSEL MW (2007) Calibration and performance of moisture sensors in soilless substrate: $\mathrm{ECH}_{2} \mathrm{O}$ and Theta probes. Sci Hortic. 112 227-234. https://doi.org/10.1016/j.scienta.2006.12.013

NEMALI KS and VAN IERSEL MW (2006) An automated system for controlling drought stress and irrigation in potted plants. Sci. Hortic. 110 292-297. https://doi.org/10.1016/j.scienta.2006.07.009

NOBORIO K, MCINNES KJ and HEILMAN JL (1996) Measurements of soil water content, heat capacity, and thermal conductivity with a single TDR probe. Soil Sci. $16122-28$. https://doi. org/10.1097/00010694-199601000-00004

OCHSNER TE, HORTON R and REN T (2003) Use of the dualprobe heat pulse technique to monitor soil water content in the vadose zone. Vadose Zone J. 2 572-579. https://doi.org/10.2136/ vzj2003.05720

PIMENTEL D, BERGER B, FILIBERTO D, NEWTON M, WOLFE B, KARABINAKIS E, CLARK S, POON E, ABBETT E and NANDAGOPAL S (2004) Water resources: Agricultural and environmental issues. BioScience 54 909-918. https://doi. org/10.1641/0006-3568(2004)054[0909:WRAAEI]2.0.CO;2

ROSENBAUM U, HUISMAN JA, VRBA J, VEREECKEN H and BOGENA HR (2010) Correction of temperature and electrical conductivity effects on dielectric permittivity measurements with $\mathrm{ECH}_{2} \mathrm{O}$ sensors. Vadose Zone J. 10 582-593. https://doi.org/10.2136/ vzj2010.0083

SAAVOSS M, MAJSZTRIK J, BELAYNEH B, LEA-COX J and LICHTENBERG E (2016) Yield, quality, and profitability of sensorcontrolled irrigation: a case study of snapdragon (Antirrhinum majus L.) production. Irrig. Sci. 34 409-420. https://doi. org/10.1007/s00271-016-0511-y

SCANLON BR, ANDRASKI BJ and BILSKIE J (2002) Miscellaneous methods for measuring matric or water potential. In: Dane JH and Topp GC (eds.) Methods of Soil Analysis, Part 4, Physical Methods, SSSA Book Series No. 5. Soil Science Society of America, Madison. 643-670.
SCHINDLER U, MÜLLER L and EULENSTEIN F (2016) Measurement and evaluation of the hydraulic properties of horticultural substrates. Arch. Agron. Soil Sci. 62 806-818. https://doi.org/10.108 0/03650340.2015.1083982

SHAW B and BAVER LD (1940) An electrothermal method for following moisture changes of the soil in situ. Soil Sci. Soc. Am. Proc. 4 78-83. https://doi.org/10.2136/ sssaj1940.036159950004000C0014x

SMITH KA and MULLINS CE (2000) Soil and Environmental Analysis: Physical Methods ( $2^{\text {nd }}$ edn). Marcel Dekker, New York. 637 pp.

SONG Y, HAM JM, KIRKHAM MB and KLUITENBERG GJ (1998) Measuring soil water content under turfgrass using the dual-probe heat-pulse technique. J. Am. Soc. Hortic. Sci. 123 937-941.

TARARA JM and HAM JM (1997) Measuring soil water content in the laboratory and field with dual-probe heat-capacity sensors. Agron. J. 89 535-542. https://doi.org/10.2134/agronj1997.0002196200890 $0040001 x$

TOPP GC, DAVID JL and ANNAN AP (1980) Electromagnetic determination of soil water content: Measurement in coaxial transmission lines. Water Resour. Res. 16 574-582. https://doi. org/10.1029/WR016i003p00574

TOPP GC, ZEBCHUCK WD, DAVIS JL and BAILEY WG (1984) The measurement of soil water content using portable TDR hand probe. Can. J. Soil Sci. 64 313-321. https://doi.org/10.4141/cjss84-033

VAN DER PLOEG MJ, GOOREN HPA, BAKKER G, HOOGENDAM CW, HUISKES C, KOOPAL LK, KRUIDHOF H and ROOIJ GH (2010) Polymer tensiometers with ceramic cones: direct observations of matric pressures in drying soils. Hydrol. Earth Syst. Sci. 14 1787-1799. https://doi.org/10.5194/hess-14-1787-2010

VAN IERSEL MW, DOVE S, KANG J and BURNETT SE (2010) Growth and water use of petunia as affected by the substrate water content and daily light integral. HortScience 45 277-282.

VAN IERSEL MW, DOVE S and BURNETT SE (2011) The use of soil moisture probes for improved uniformity and irrigation control in greenhouses. Acta Hortic. 893 1049-1056. https://doi.org/10.17660/ ActaHortic.2011.893.119

VAN IERSEL MW, CHAPPELL M and LEA-COX JD (2013) Sensors for improved efficiency of irrigation in greenhouse and nursery production. HortTechnology 23 735-746.

WHEELER WD, WILLIAMS-WOODWARD J, THOMAS PA, VAN IERSEL M and CHAPPELL MR (2017) Impact of substrate volumetric water on Pythium aphanidermatum infection in Petunia xhybrida: A case study on the use of automated irrigation in phytopathology studies. Plant Health Prog. 18 120-125. https://doi. org/10.1094/PHP-01-17-0006-RS 